\title{
Street papers: instrumento de interação social
}

Adriano da Silva Rozendo

Doutorando em Psicologia pela UNESP/Assis. Mestre em Psicologia pela Universidade Estadual Paulista Júlio de Mesquita Filho, onde se graduou em Psicologia. É presidente do Conselho Municipal do Idoso de Assis/SP e conselheiro estadual do idoso de São Paulo.

E-mail: rozendoadriano@aol.com

Suzana da Silva Rozendo

Graduada em Comunicaşão Social (jornalismo) pela Universidade Federal de Mato Grosso do Sul. Atualmente é mestranda na linha de Processos e Produtos Jornalísticos da Universidade

Federal de Santa Catarina e tem por objeto de estudos os street papers.

E-mail: sukirozendo@hotmail.com

Resumo: Surgidos em meados de 1990, os street papers constituem uma nova tendência na comunicação social, capaz de promover a interação como também trocas de experiências entre os atores envolvidos no processo de sua elaboração. Apesar da comprovada eficácia dos jornais de rua, não existe ações ou recursos governamentais voltados para o fomento destes veículos de comunicação.

Palavras-chave: Street paper, interação, social, mídia, comunicação.
Abstract: Appeared in the middle of 1990, the street papers constitute a new tendency in the social communication, able to promote the interaction and exchanges between the actors involved in the process of its preparation. Even knowing about the efficiency of this newspapers there are not actions, or government resources turned to the incitement of these practice.

Keywords: Street paper, interaction, social, media, communication.

Diante dos avanços tecnológicos que provocam mudanças nos produtos $e$ processos jornalísticos, existe uma tendência que cresce paralelamente. Estamos referindo-nos a uma tecnologia ainda pouco conhecida pela sociedade, os chamados street papers. Surgidos em meados de 1990, constituem uma nova proposta editorial que visa estimular a reinserção social do indivíduo em situação de rua. Jornais ou revistas passaram a ser produzidos e comercializados pelos chamados homeless ou sem teto, indivíduos considerados em situação de risco social.

Nos street papers, a objetividade e neutralidade, tão discutidas nos assuntos relacionados ao jornalismo, não possuem tanta importância. Nestes veículos de comunicação alternativa, o produto jornalístico toma partido das questões sociais como a desigualdade e exclusão social em contraposição às tendências jornalísticas que defendem a separação entre produção e realidade social. Assim, é levada em consideração a implicação política do trabalho jornalístico'

Recebido: 17.06.2010

Aprovado: 01.04.2011

1. ABRAMO, C. A regra do jogo: o jornalismo e a ética do marceneiro. São Paulo: Companhia das Letras, 1988. p. 109. 
Com o lançamento no ano de 1991 da revista The Big Issue, em Londres, os street papers ou jornais de rua passariam a constituir um movimento propagado em escala mundial. O periódico inglês impulsionou o surgimento de vários outros projetos editoriais semelhantes criados com o objetivo de estabelecer relações entre sujeitos de níveis sociais diferentes, através do processo de compra e venda das revistas.

Em 1994, surgiu a International Networking of Street Papers (INSP), primeira rede internacional de street papers cujo objetivo era auxiliar e divulgar a nova proposta editorial. Em agosto de 1996, representantes de 26 periódicos dos Estados

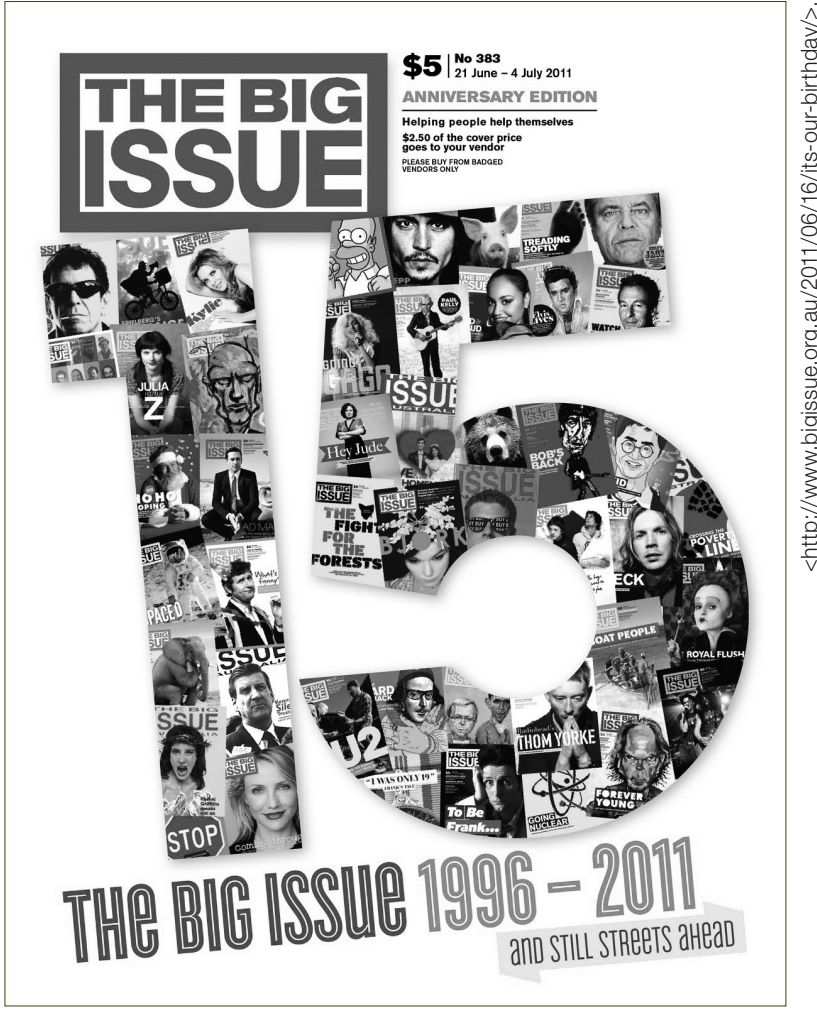

Capa da edição especial de aniversário de 15 anos da The Big Issue australiana.
Unidos e do Canadá criaram outra rede internacional, The North American Street Newspaper (Nasna), com sede na cidade de Seattle, Estado de Washington.

Durante dez anos, a Nasna e a INSP desenvolveram ações separadamente nas regiões onde atuavam, até que, em 2006, foi realizado um acordo de trabalho em conjunto. Hoje, as duas redes possuem juntas mais de 70 publicações filiadas nos cinco continentes. A sede atual da junção das duas organizações está situada na cidade de Glasgow, na Escócia.

De acordo com Walty ${ }^{2}$, a INSP associa países desenvolvidos e em desenvolvimento, investindo na troca de conhecimentos e experiências entre as partes envolvidas no processo de produção, compra e venda destes periódicos.

Importa realçar que os vendedores dos jornais de rua também escrevem para a revista e encontram-se envolvidos em outras atividades esportivas e culturais, como os grupos teatrais, as oficinas de criação de textos, além de um campeonato mundial de futebol ${ }^{3}$.

No Brasil, estão vinculadas à Rede Internacional de Publicações de Rua: a Organização Civil de Ação Social, por meio da revista Ocas, distribuída no Rio de Janeiro e São Paulo; a Agência Livre para Informação, Cidadania e Educação, através do jornal Boca de Rua, de Porto Alegre e, a mais recente publicação, o jornal Aurora da Rua, elaborado pela Organização da Igreja Trindade de Salvador. As três organizações têm o objetivo comum de promover a reintegração social das pessoas em situação de rua através da venda dos jornais ou das revistas. 


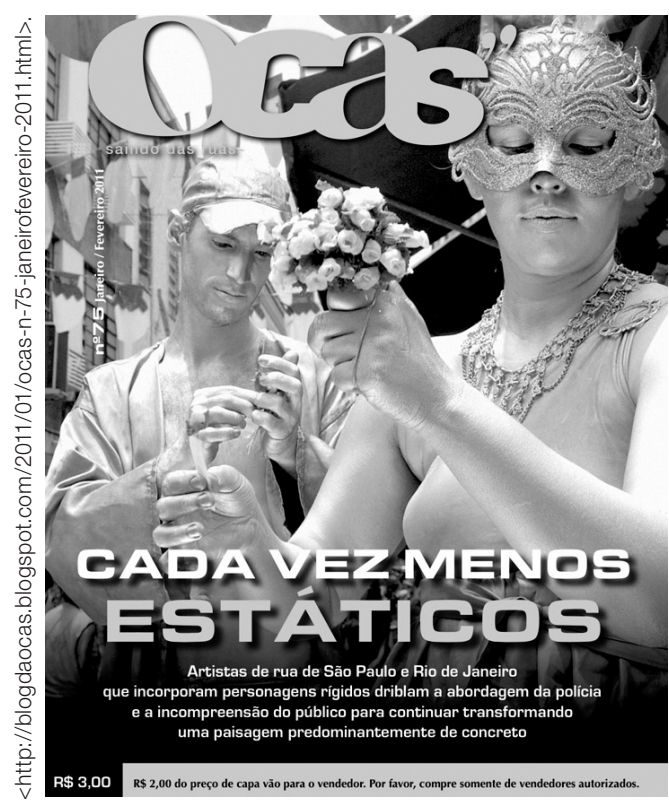

Capa da edição n. 75 da revista Ocas.
A pessoa em situação de rua compra (com desconto) o produto da organização responsável pela produção e o revende pelo preço de capa. As publicações só podem ser adquiridas diretamente com os vendedores cadastrados, que circulam em pontos de venda alternativos, como cinemas, cafés, bares, museus, universidades, feiras e eventos. Os vendedores devem ter idade mínima de dezoito anos, receber treinamento, assinar um código de conduta e portar crachá. Eles, na maioria das vezes, participam das reuniões de pauta e da produção do periódico. Neste caso, cabe ao jornalista responsável pela edição elaborar as melhores formas de relatar os acontecimentos e organizar temporal e espacialmente o trabalho ${ }^{4}$.

Ao adquirir o jornal, o leitor não compra apenas um produto comercial, mas um dispositivo que promove a interação social e o exercício da cidadania. Canclini acredita que as práticas de consumo poderiam ser exploradas como uma forma de exercício de cidadania, através da criação de redes de intercâmbio, de informação e de aprendizagem. Para o autor, muitas perguntas sobre os direitos dos cidadãos "recebem sua resposta mais através do consumo privado

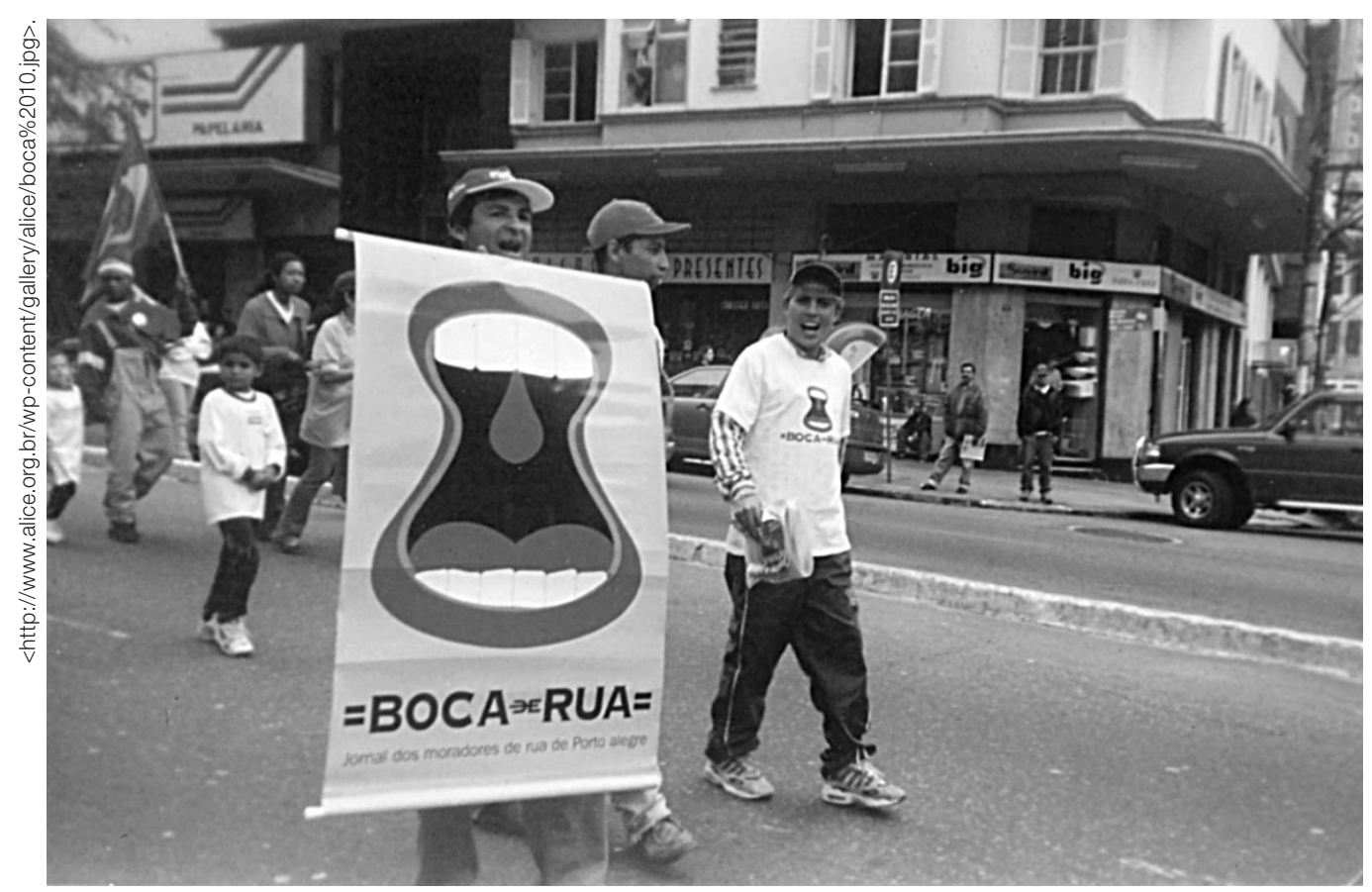

Além de produzirem o jornal, os integrantes do Boca de Rua também participam de manifestações, como a Marcha dos Excluídos.
4. WOLF, M. Teorias da comunicação de massa. Lisboa: Editora Presença, 2002. p. 170. 
5. CANCLINI, N. G. Consumidores e cidadãos. Rio de Janeiro: Editora UFRJ, 2005. p. 29.

6. BRASIL. Moradores e ex-moradores de rua terão Política Naciona que garanta seus direitos (on-line). Ministério do Desenvolvimento Social. Disponivel em: <http:// www.mds.gov.br/noticias/ moradores-e-ex-moradores-de-rua-terao-politica-nacional-que-garanta-seus-direitos/?searchterm $=$ moradoresderua $>$. Aces so em: 8 dez. 2009 .

7. MELO, J. M. Estudos de jornalismo comparado. São Paulo: Editora Pioneira, 1972. p. 67.

8. CAZENEUVE, J. Guia alfabético das comunicações de massa. Lisboa: Edições 70, 1976. p. 163.

9. TRAQUINA, N. Por que as notícias são como são. Florianópolis: Editora Insular, 2004. p. 77

10. CANTARINO, C. A organização internacional dos moradores de rua. Ciência e Cultura, São Paulo, v. 57, n. 01, p. 6-7, jan./mar. 2005 comunicação \& educação • Ano XVI • número 2 • jul/dez 2011

de bens e dos meios de comunicação de massa do que pelas regras abstratas de democracia ou pela participação em espaços públicos" ${ }^{5}$.

De agosto de 2007 a março de 2008, foi realizada uma pesquisa nacional sobre a população em situação de rua pelo Instituto Meta. O público-alvo da pesquisa foram pessoas com dezoito anos completos em mais de 71 cidades brasileiras, sendo 48 com mais de 300 mil habitantes e 23 capitais. Dos entrevistados, $74 \%$ sabiam ler e escrever. A pesquisa indicou que a população de rua não é composta de mendigos e pedintes, como pode ser imaginado pelo senso comum. Do total de entrevistados, $72 \%$ trabalham em coleta de materiais recicláveis, na construção civil, como flanelinhas ou auxiliares de limpeza ${ }^{6}$.

Melo acredita que os meios de comunicação coletiva "possam desempenhar um papel decisivo no processo de desenvolvimento nas esferas regionais, funcionando como agentes de mudança cultural e social" ${ }^{\prime \prime}$. Nesse sentido, o sociólogo francês Jean Cazeneuve afirma que os veículos comunicativos podem ser poderosos transformadores sociais, pois "dotar a sociedade com os meios de conhecer a si própria é fornecer-lhe os instrumentos para planear o seu futuro"'. É nesta linha de raciocínio que se insere a proposta editorial do street paper, entendido com um veículo de comunicação capaz de fornecer subsídios para importantes transformações sociais.

\section{JORNAL DE RUA E SUA FUNÇÃO SOCIAL}

Os street papers constituem-se como poderosos promotores de mudanças nas concepções sobre os moradores de ruas. Traquina ${ }^{9}$ considera que a realidade é construída através de inúmeros processos de interação social, tais como a informação, as fontes, os profissionais e demais agentes envolvidos no processo de produção das notícias. Desta forma, o modo pelo qual a informação circula e é produzida é um poderoso mecanismo de produção de sentidos, que pode ser utilizado a favor de determinadas categorias sociais.

A participação dos vendedores nas reuniões de pauta dos periódicos de rua é uma das formas de estabelecer canais de expressão entre vendedores, editores, profissionais da área do jornalismo e estudantes universitários das ciências humanas. Nestes espaços de congregação, os moradores de rua podem sugerir conteúdos e fazer relatos sobre as experiências vivenciadas na situação de rua. Assim, os leitores destes periódicos e a sociedade em geral podem ter contato com a realidade materializada na vida desta população. De acordo com Cantarino, a "condição de habitante das ruas oferece a possibilidade de um olhar único sobre o cotidiano das grandes cidades do mundo" ${ }^{10}$. Dessa forma, os jornais de rua podem ser utilizados também como espaços de expressão de singularidades.

Trazer à tona a realidade vivenciada pelas pessoas em situação de rua através dos street papers torna possível o reconhecimento deste grupo social como cidadão. Vale ressaltar aqui que estes sujeitos vêm sendo historicamente 
estigmatizados pela sociedade, através de vinculações a imagens pejorativas como da vadiagem, promiscuidade, ociosidade, alcoolismo, desvios de caráter, dentre outras ${ }^{11}$. Mattos e Ferreira retratam bem como a sociedade costuma enxergar a população de rua:

(...) nós as olhamos amedrontados, de soslaio, com uma expressão de constrangimento. Alguns as veem como perigosas, apressam o passo. Outros logo as consideram vagabundas e que ali estão por não quererem trabalhar, olhando-as com hostilidade. Muitos atravessam a rua com receio de serem abordados por pedido de esmola, ou mesmo por preconceberem que são pessoas sujas e malcheirosas ${ }^{12}$.

As noções que circulam sobre nosso público-alvo fazem com que a sociedade, mesmo que involuntariamente, o marginalize. Noutros casos, em atitudes mais violentas, pessoas civilizadas e inseridas nos padrões de normalidade chegam a agredir verbal e fisicamente ou até mesmo a queimar os moradores de rua, como em alguns lamentáveis casos noticiados pela imprensa ${ }^{13}$.

De acordo com Patrícia Merkin, presidente da Organização Hecho de Buenos Aires, a venda dos periódicos de rua é um excelente canal de promoção social e valorização desses moradores de rua: "Hay personas que fueron vendedores y hoy tienen tareas rentadas dentro de la organización, hay personas que fueron vendedores y hoy accedieron a completar sus estudios, y como esos, muchos ejemplos que denotan niveles de participación". ${ }^{14}$

Talvi, em seu artigo intitulado $O$ poder da comunicação na rua, diz que os street papers são revolucionários para todas as partes interessadas. "Isto é o que parece ser o jornalismo internacional popular. Ele não é somente possível, ele já está acontecendo e é empolgante e durável"15.

Silva acredita que o jornal Boca de Rua traz muitos benefícios aos moradores de rua que o produzem, tanto psicologicamente quanto de forma material, já que através do trabalho estes sujeitos podem recuperar a autoestima e também garantir, por conta própria, a sua sustentabilidade. Contudo, "o retorno pode ser ainda maior [...] caso a abordagem jornalística dos problemas [...] seja mais aprofundada e leve o público leitor a se sentir mais responsável também pela solução dos problemas"16.

Na mesma linha de pensamento, Haddad, ao analisar a Revista Ocas, concluiu que:

Reconhecer que existe uma outra possibilidade de inclusão, oferecida por um veículo de comunicação, e não mais pelas formas assistencialistas do Estado, é uma maneira de dizer: sim, nós temos uma outra forma de incluir. Você quer fazer parte?

Ao defender a inclusão social, a revista Ocas se propõe como uma ferramenta de transformação na qual o vendedor é, ao mesmo tempo, o agente dessa transformação e $o$ transformador ${ }^{17}$.

Irmão Henrique Peregrino da Trindade, integrante do Conselho Editorial do street paper Aurora da Rua, diz que o projeto é pioneiro na região Nordeste.
11. COSTA, J. F. Ordem médica e norma familiar. Rio de Janeiro: Graal, 1989. p. 25-80.

12. MATTOS, R M.; FERREIRA, R. F. Quem vocês pensam que (elas) são? Representações sobre as pessoas em situação de rua. Psicologia e Sociedade, Porto Alegre, $n$. 16 , v. 2 , p. $47-58$, maio/ ago. 2004.

13. Ibid.

14. HECHO en Buenos Aires. La prensa ambulante. Revista Contratiempo. Disponível em: <http:// www.revistacontratiempo. com.ar/hechoba.htm> (Trad. nossa).

15. TALVI, Silja J. A. Reporting From The Ground Up. The power of street reporting [Fazendo uma reportagem desde a base. A força da reportagem de rua]. In These Times. Disponível em: <http:// www.inthesetimes.com/ article/3781/reporting from_the_ground_up $>$ (Trad. nossa).

16. SILVA, G. Contribuição ao estudo da violência: Jornal Boca de Rua e as políticas públicas para a adolescência em Porto Alegre, 2007, 90f. Trabatho de conclusão (graduação em jornalismo). Universidade Federal do Rio Grande do Sul, Porto Alegre, p. 88.

17. HADDAD, J. C. Street Papers, mídia e reinclusão social: a revista Ocas, 2007, 145f. Dissertação (Mestrado em Comunicação). Faculdade Cásper Líbero, São Paulo, p. 108. 
Trata-se de um canal de comunicação entre os moradores de rua e a sociedade. Além de refletir sobre a problemática de quem mora na rua, o projeto pretende colaborar com a geração de renda, levando à reinserção social dos envolvidos, oferecendo, assim, um meio alternativo de sustento através do trabalho ${ }^{18}$.

Ao tratar do jornal O Trecheiro: Notícias do Povo da Rua, Mattos e Ferreira ${ }^{19}$ afirmam que o periódico constitui um excelente meio de comunicação realizado com e para a população em situação de rua da cidade de São Paulo. Segundo o autor, $O$ Trecheiro tem o intuito de dar vez e voz ao povo da rua, sendo um instrumento de comunicação dos acontecimentos vivenciados nas ruas paulistanas. O jornal possui uma linha editorial calcada na denúncia e discussão de estratégias para a assistência à população em situação de rua.

$\mathrm{Na}$ mesma linha de raciocínio, Walty retrata a importância destes veículos de comunicação como espaços de reivindicações de políticas sociais e profundos debates políticos. A autora destaca o contraste entre as linguagens formais e informais presentes nestas comunicações, que misturam coloquialismos com cientificismos formais, conforme podemos observar nos trechos abaixo, que esboçam a linguagem formal e informal utilizada nos street papers selecionados pela autora:

O sem-teto:

Autoridades! Federal, Estadual e Municipal, Executivo, Legislativo e Judiciário. Não aguentamos esperar!

Se pagar aluguel, não come. Se comer, não paga aluguel. É esse nosso dilema. Somos trabalhadores sem-teto desta magnífica cidade. Somos empurrados para as favelas, cortiços, pensões e para o relento das ruas. Sofremos com o despejo do senhorio.

O especialista:

Assim como o Estado e o mercado, o terceiro setor se relaciona com todas as realidades possíveis, permitindo que os "entes" acima se "permeabilizem”, criando uma relação menos estanque entre ambos através de outro "feixe" da sociedade, que ainda não se identificou totalmente, mas está a caminho ${ }^{20}$.

É fundamental levar em consideração que os jornais de rua constituem um espaço legítimo e espontâneo de contestação, de reivindicações sociais, de protesto, enfim, da propagação do grito dos excluídos.

A importância destes periódicos como instrumentos de inserção e reinserção social é apontada por especialistas e pelas próprias organizações que as produzem. Todavia, deve-se levar em consideração que muitos moradores de rua escolheram esta alternativa de vida por conta própria e não pretendem se

18. A VOZ que ecoa da rua. Blog da Rua. Disponivel em:<http://www. blogdarua.com/2007/03/ voz-que-ecoa-da-rua. html>. Acesso em: 13 de janeiro 2010.

19. MATTOS, op. cit.

20. WALTY, op. cit., p. 80 integrar ou se reintegrar aos padrões de conduta e vida socialmente aceitos e compreendidos como normais.

Desse modo, destacamos aqui a capacidade de interação social promovida pelos jornais de rua, tendo em vista que estes possibilitam a propagação das experiências de rua vivenciadas pelos seus moradores, pela boca dos mesmos. Permitem ainda momentos de convivência e consequente trocas de experiências, 
entre atores sociais distintos, tendo em vista que a aquisição destes materiais implica o contato direto dos cidadãos comuns com os moradores de rua.

Destacamos ainda outro potencial inerente aos street papers. Por serem geradores de renda e ainda favorecer a autonomia financeira aos vendedores, conferindo-lhes, assim, o status de trabalhadores informais. Nesse sentido, a produção e comercialização desses periódicos alteram drasticamente a maneira como a sociedade enxerga as pessoas em situação de rua, como são encaradas, passando a designá-las como sujeitos produtivos. Deste modo, a figura do morador de rua pode ser menos hostilizada.

\section{A EXCLUSÃO SOCIAL EM ESTUDO}

Apesar da importância social dos jornais de rua, no Brasil ainda há poucas pesquisas científicas realizadas sobre o assunto. No campo das ações governamentais, não encontramos investimentos voltados à propagação destes importantes veículos de comunicação.

As políticas voltadas à referida população têm sido executadas pelas pastas responsáveis pela assistência social, nas três esferas da administração pública. Conforme aponta a literatura, a partir de meados do século XX, houve uma mudança paradigmática na assistência social, que substituiu a filantropia cristã e assistencialista por ações coordenadas de Estado ${ }^{21}$. Com isso, houve uma transição nos sentidos realizados pelas práticas assistencialistas, que passaram de obras de caridade, desenvolvidas usualmente por membros da Igreja e da aristocracia, para uma ação planejada e coordenada pelo Estado.

Com esta transição, percebemos que na contemporaneidade as políticas de assistência social vêm se materializando em medidas, que visam manter um controle político e ideológico dos seus usuários, de acordo com os interesses estabelecidos pelo Estado-neoliberal ${ }^{22}$. Assim, justifica-se a falta de interesse governamental no apoio à implantação, divulgação, propagação e distribuição dos street papers, por serem potenciais promotores de questionamentos, contestações e, consequentemente, de mudanças no cenário social, político e econômico.

Ao tratar dos investimentos em políticas de assistência às pessoas em situação de rua, o Estado foca suas ações na normatização e ordenação desta população, de acordo com os interesses do capitalismo. Neste intuito é que são implantados os afamados centros de triagem, que visam ao controle da movimentação destes indivíduos, seguindo assim uma lógica de gestão administrativa de Estado $^{23}$. Nestes centros, os moradores de rua são triados, rastreados, catalogados e higienizados de acordo com os padrões normativos da sociedade normal-capitalista. O mesmo objetivo é imanente aos incentivos governamentais na criação de cooperativas de catadores de matérias recicláveis, que definitivamente institucionalizam o potencial de produção desviante destes sujeitos, em verdadeiros currais psicossociais, voltados para a produção em massa.
21. GROISMAN, D. A infância do asilo. Dissertação (Mestrado em Saúde Coletiva), 120f, p. 30. Universidade do Estado do Rio de Janeiro, Rio de Janeiro, 1999.

22. SANT'ANA, R. S. A trajetória histórica do serviço social e a construção do seu projeto ético-político. Serviço Social e Realidade, Franca, v. 08, n. 01, p. 73-88, jan./mar. 1999.

23. JUSTO, J. S. Dromopolítica contemporânea - O caso dos andarilhos. In.: FRANÇA, S. et al. (org.). Estratégias de controle social. São Paulo: Arte e Ciência, 2004, p. 9-41. 
No dia 24 de dezembro de 2009, foi promulgado, em Brasília, o Decreto n. 7.053, intitulado Política Nacional da População em Situação de Rua. Além da implantação de uma política em âmbito nacional, dirigida à população de rua, o decreto prevê algumas mudanças nos direcionamentos de recursos e atenções dirigidos à referida clientela, conforme podemos observar nos objetivos arrolados pela lei:

Art. 7: São objetivos da Política Nacional para a População em Situação de Rua:

I - Assegurar o acesso amplo, simplificado e seguro aos serviços e programas que integram as políticas públicas de saúde, educação, previdência, assistência social, moradia, segurança, cultura, esporte, lazer, trabalho e renda. ${ }^{24}$

O Decreto, dentre outras medidas, reitera direitos universais do homem, já previstos na Constituição Federal do Brasil, tais como o acesso ao trabalho, à renda e à saúde. Ao leitor mais atento, não escapariam as tônicas que o Estado atrela a esta população, conforme se pode constatar logo no primeiro artigo desta lei:

Para fins deste Decreto, considera-se população em situação de rua o grupo populacional heterogêneo que possui em comum a pobreza extrema, os vínculos familiares interrompidos ou fragilizados e a inexistência de moradia convencional regular, e que utiliza os logradouros públicos e as áreas degradadas como espaço de moradia e de sustento de forma temporária ou permanente, bem como as unidades de acolhimento para pernoite temporário ou como moradia provisória.

Como se pode notar, pesa o estigma social produzido historicamente sobre esta população, nos discursos legais do Estado. Perante um leque de representações que retratam a população de rua de forma predominantemente pejorativa, os street papers ganham ainda mais importância, por vincularem noções favoráveis aos seus referentes.

24. BRASIL. Decreto 7.053 de 23 de dezembro de 2009. Institui a Política Nacional para a Popula ção em Situação de Rua e seu Comitê Intersetorial de Acompanhamento e Monitoramento, e dá outras providências. D.O.U DE 24/12/2009, p. 16. Gri-

fo dos autores. Disponível em: <http://www.planalto.gov.br/ccivil_03/_ Ato 2007-2010/2009/ Decreto/D7053.htm>.

\section{CONCLUSÃO}

É possível enxergar nos street papers uma poderosa tendência de transformação social, de aceitação e interação entre os moradores de rua e demais estratos da população. A falta de incentivos governamentais é um importante indicador da potencialidade instituinte destes canais de comunicação, que vêm sendo deixados de lado pelas subvenções públicas.

Perante a falta de interesse estatal, é necessário buscar apoio em instâncias menos contaminadas pelos interesses neoliberais, tais como organizações de defesa de direitos e as próprias universidades. Vale ressaltar que a legitimidade conferida aos jornais de rua emerge da espontaneidade destas publicações, que eclodem da iniciativa e empenho dos próprios moradores em conjunto com outros segmentos da sociedade civil. 


\section{REFERÊNCIAS BIBLIOGRÁFICAS}

ABRAMO, C. A regra do jogo: o jornalismo e a ética do marceneiro. São Paulo: Companhia das Letras, 1988.

CANCLINI, N. G. Consumidores e cidadãos. Rio de Janeiro: Editora UFRJ, 2005.

CANTARINO, C. A organização internacional dos moradores de rua. Ciência e Cultura, São Paulo, v. 57, n. 01, p. 6-7, jan./mar. 2005.

CAZENEUVE, J. Guia alfabético das comunicações de massa. Lisboa: Edições 70, 1976.

COSTA, J. F. Ordem médica e norma familiar. Rio de Janeiro: Graal, 1989.

GROISMAN, D. A infância do asilo. Dissertação (Mestrado em Saúde Coletiva), 120f. Universidade do Estado do Rio de Janeiro, Rio de Janeiro, 1999.

HADDAD, J. C. Street papers, mídia e reinclusão social: a revista Ocas, 2007, 145f. Dissertação (Mestrado em Comunicação). Faculdade Cásper Líbero, São Paulo.

JUSTO, J. S. Dromopolítica contemporânea - O caso dos andarilhos. In.: FRANÇA, S. et al. (Org.). Estratégias de controle social. São Paulo: Arte e Ciência, 2004.

MATTOS, R. M.; FERREIRA, R. F. Quem vocês pensam que (elas) são? Representações sobre as pessoas em situação de rua. Psicologia e Sociedade, Porto Alegre, n. 16, v. 2, p. 47-58, maio/ago. 2004.

MELO, J. M. Estudos de jornalismo comparado. São Paulo: Editora Pioneira, 1972.

SANT'ANA, R. S. A trajetória histórica do serviço social e a construção do seu projeto ético-político. Serviço Social e Realidade, Franca, v. 08, n. 01, p. 73-88, jan./mar. 1999.

SILVA, G. Contribuição ao estudo da violência: jornal Boca de Rua e as políticas públicas para a adolescência em Porto Alegre, 2007, 90f. Trabalho de conclusão (graduação em jornalismo). Universidade Federal do Rio Grande do Sul, Porto Alegre.

TRAQUINA, N. Por que as notícias são como são. Florianópolis: Editora Insular, 2004.

WALTY, I. Os intelectuais e os moradores de rua: uma parceria em construção? Letras de Hoje, Porto Alegre, v. 42, n. 4, p. 77-84, dez. 2007.

WOLF, M. Teorias da comunicação de massa. Lisboa: Editora Presença, 2002.

\section{ENDEREÇOS ELETRÔNICOS}

BRASIL. Moradores e ex-moradores de rua terão Política Nacional que garanta seus direitos (online). Ministério do Desenvolvimento Social. Disponível em: <http:/ / www.mds.gov.br/noticias / moradores-e-ex-moradores-de-rua-terao- 
comunicação \& educação • Ano XVI • número 2 • jul/dez 2011

politica-nacional-que-garanta-seus-direitos $/$ ?searchterm=moradoresderua $>$. Acesso em: 8 dez. 2009.

BRASIL. Decreto 7.053 de 23 de dezembro de 2009. Institui a Política Nacional para a População em Situação de Rua e seu Comitê Intersetorial de Acompanhamento e Monitoramento, e dá outras providências. D.O.U. de 24/12/2009, p. 16. Disponível em: <http://www.planalto.gov.br/ccivil_03/_Ato2007-2010/2009/ Decreto/D7053.htm>.

HECHO en Buenos Aires. La prensa ambulante. Revista Contratiempo. Disponível em: <http://www.revistacontratiempo.com.ar/hechoba.htm>.

TALVI, Silja J. A. Reporting From The Ground Up. The power of street reporting [Fazendo uma reportagem desde a base. A força da reportagem de rua]. In These Times. Disponível em: <http://www.inthesetimes.com/article/3781/reporting from_the_ground_up $>$.

A VOZ que ecoa da rua. Blog da Rua. Disponível em: <http://www.blogdarua. com/2007/03/voz-que-ecoa-da-rua.html $>$. Acesso em: 13 jan. 2010. 